\title{
Study of the oviposition response of black soldier fly (BSF) in the presence of banana and pupal remains
}

Pei Chin Tan, Siong Fong Sim*

Faculty of Resource Science and Technology, Universiti Malaysia Sarawak, 94300 Kota Samarahan, Malaysia

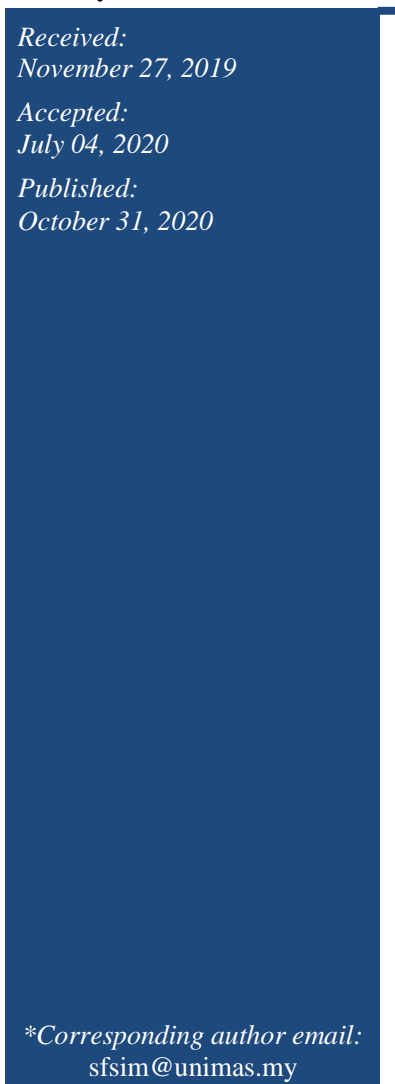

Abstract

Black soldier fly (BSF), Hermetia illucens, is an important beneficial insect. Numerous studies have been conducted to understand the oviposition behavior and preferences of BSF. This paper reports the effects of decomposition level of food and presence of pupal remnants on the oviposition responses of BSF. Cages comprising of four oviposition sites, housed with five male and female BSF were prepared. Gravid females were provided with equal opportunities to oviposit in two sites with ripened banana (mildly ripened (MR) or over-ripened banana (AR)) and two other sites with fresh banana $(\mathrm{OV})$. Three replicates in clockwise replication design were set up. The presence of pupal cases in high, medium and low abundance were studied. The number of eggs deposited at different sites were counted and expressed in percentage and oviposition attraction index (OAI). Gravid BSF females showed greater attraction to sites with over-ripened banana likely associating with the odor. BSF females also exhibited a preference for egg laying at sites with less pupae cases. Sites with the most abundance pupae cases were far less enticing as the pupae cases may deter the ovipositing BSF. The findings of this study is important for development of effective egg trapping and collection strategies in BSF farming.

Keywords: Hermetia illucens, Stages of ripening, Odor, Pupal case, Oviposition

\section{How to cite this:}

Tan PC and Sim SF, 2020. Study of the oviposition response of black soldier fly (BSF) in the presence of banana and pupal remains. Asian J. Agric. Biol. 8(4): 398-404. DOI: https://doi.org/10.35495/ajab.2019.11.529

This is an Open Access article distributed under the terms of the Creative Commons Attribution 3.0 License. (https://creativecommons.org/licenses/by/3.0), which permits unrestricted use, distribution, and reproduction in any medium, provided the original work is properly cited.

\section{Introduction}

Insects are natural diet for fish and poultry (van Huis et al., 2013). They have high feed conversion efficiency and are rich source of protein, fat, vitamin and minerals (Rumpold and Schlüter, 2013). These characteristics are also typical to black soldier fly (BSF), Hermetia illucens (Diptera: Stratiomyidae). BSF is a valuable source for biodiesel production due to its high lipid content (Wang and Shelomi, 2017). According to previous study, the amount of protein and fat stored in BSF larvae can be as high as $35-45 \%$ on dry matter basis (Newton et al., 2005). The crude protein and fat level reported in BSF pre-pupae was in the range of $38 \%-46 \%$ and $21 \%-48 \%$, respectively (Oonincx et al., 2015; Driemeyer, 2016). BSF is also used as an effective biological control agent to reduce the oviposition of house flies (Tomberlin and Sheppard, 2002).

BSF has been commonly used for bioconversion of organic wastes (Nguyen et al., 2015; Badenhorst, 2017; Nyakeri et al., 2017a), the larvae can consume a 
wide range of organic residues from streams (Chia et al., 2018), feces, plant (Nguyen et al., 2015), landfill wastes (Diener et al., 2009) as well as carrion (Tomberlin et al., 2005). They can be fed as highquality feed for swine (Newton et al., 2005), fish (Wang and Shelomi, 2017), and poultry (Moula et al., 2018). Tomberlin and Sheppard (2001) reported that BSF can contribute up to $25 \%$ reduction in wastes annually. Besides being the high quality feedstuff, the BSF waste is rich in nitrates and phosphorous serving as a potential fertilizer (Lalander et al., 2015). BSF has also been proposed as a protein supplement for human consumption (Wang and Shelomi, 2017). The nutritional composition of BSF depends largely on the growth and larval development as well as the quality of wastes fed (Lalander et al., 2015; Badenhorst, 2017). Therefore, it is important to gain better insights into the oviposition preference facilitating production of high quality larvae.

Numerous studies have been many conducted to understand the oviposition behavior and preferences of BSF (Park et al., 2016; Nyakeri et al., 2017b). Conditions at egg deposition sites including adequate sunlight and availability of food were highly attractive to gravid BSF females (Park et al., 2016). The odor intensity further stimulated the oviposition response (Aldana et al., 2013; Nyakeri et al., 2017b). Tomberlin and Sheppard (2002) on the other hand identified the deterrent effect of house fly larvae in oviposition behavior of BSF females. The factors governing the oviposition behavior of BSF is important to the BSF farming industry to develop strategies in maintaining their rearing facilities and to improve their production efficiency and quality. The effects of decomposition level of food and the presence of pupal remnants on the oviposition response of BSF is yet scarce. This paper reports the effects of banana at different maturity levels and the presence of pupal remnants on the oviposition response of BSF.

\section{Material and Methods}

\section{Sample of adults BSF}

The Borneo strain BSF, H. illucens were obtained from Fly Technology Agriculture Ltd, Kuching, Malaysia. A total of 200 BSF pupae were collected from the farm. Each pupae was placed in a $1.5-\mathrm{mL}$ Eppendorf tube, and the gender of the newly emerged adult was determined using a stereomicroscope (SZLED; Kenis, Osaka, Japan). Males and females were then placed in separate cages of dimensions $(30 \times 30$ $\times 30 \mathrm{~cm}$ ), provided with water. Additional experimental BSF adults were produced as necessary.

\section{Experimental setup}

Cages with dimensions of $(30 \times 30 \times 30 \mathrm{~cm})$ were equipped with oviposition arena comprising of foam mats $(26 \mathrm{~cm} \times 26 \mathrm{~cm})$ with an opening of $2.5 \mathrm{~cm}$ in diameter at each corner. An acrylic plastic cup was held at each opening. This setup is according to Sheppard et al. (2002).

\section{Experimental factors}

The effects of banana at different maturity level and the presence of pupal cases on the oviposition response were examined. Fresh, mildly and overripened banana (Bornean banana cultivar, Family: Musaceae) were used. Mildly ripened bananas were prepared by leaving the peeled bananas for two days whilst over-ripened bananas were left for six days. BSF pupal exuviae were collected from the farm and cleaned in the laboratory to remove any unwanted debris. They were cut into pieces of $0.2-0.5 \mathrm{~cm}$ and referred to as pupal cases.

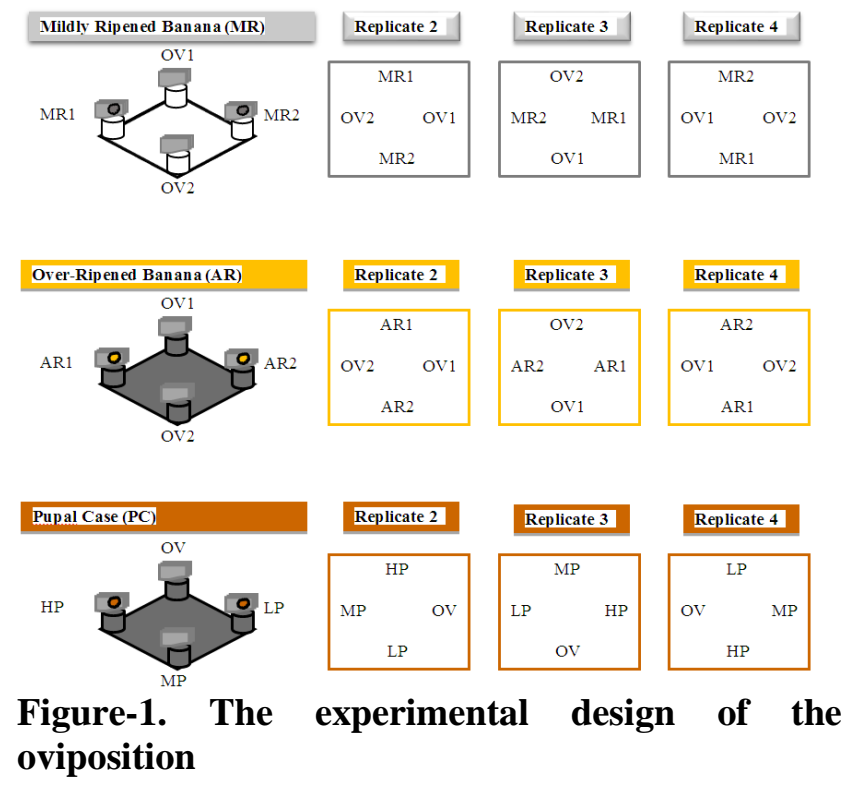

The oviposition tests were performed according to Dieng et al. (2017) with some modifications. The clockwise replication design was adopted; two cups at the opposite positions were filled with $5 \mathrm{~g}$ of mildly (MR)/over (AR) ripened banana whilst two others were filled with $5 \mathrm{~g}$ of fresh banana only (OV) as illustrated in Figure 1. On top of the cups, rectangular corrugated cardboards of $50 \times 30 \mathrm{~mm}$ were placed, 


\section{Pei Chin Tan and Siong Fong Sim}

serving as the egg deposition sites. The stages of maturity reflects the odor level where over-ripened banana tends to produce more intense odor. To examine the effects of pupal case (PC) on the oviposition response, three cups were filled with pupae cases (in low (LP), medium (MP) and high (HP) abundance of $1 \mathrm{~g}, 5 \mathrm{~g}$ and $10 \mathrm{~g}$, respectively) whilst the remaining was left empty as control (OV) in clockwise replication design as shown in Figure 1.

\section{Oviposition bioassay}

Five males and females BSF were released into each cage and supplied with water held in an acrylic plastic cup placed in the center of the oviposition arena. All cages were maintained at controlled temperature of $26^{\circ} \mathrm{C}-28^{\circ} \mathrm{C}, 75 \%-85 \%$ relative humidity, and photoperiod (light : dark) of 14:10 hours for a duration of seven days. At the end of the experimental period, the number of eggs deposited on the cardboards were counted under a dissecting microscope (Meiji EMZ; Meiji Techno Co., Ltd., Tokyo, Japan).

The mean number of eggs identified at each site was used as the score of oviposition responses. The oviposition responses were reported in percentage, expressed as the total number of eggs deposited at a given site (all replicates) divided by the total number of eggs for all four oviposition sites. The oviposition attraction index (OAI), as suggested by Kramer and Mulla (1979), was calculated to determine the oviposition response of gravid females in each oviposition site. $\mathrm{OAI}=\mathrm{T}-\mathrm{OV} / \mathrm{T}+\mathrm{OV}$, where $\mathrm{T}=$ the number of eggs laid in test site and $\mathrm{OV}=$ the number of eggs laid in control site. The index ranges from -1 to +1 , with negative value indicating repellency in test site against control; 0 indicating no preference and positive value indicating attractiveness in test site than control. The differences in oviposition responses between control $(\mathrm{OV})$ and test sites (MR, AR, LP, MP and HP) were compared using Analysis of Variance (ANOVA) at 95\% significant different with Tukey's test applied for multiple comparisons.

\section{Results}

Table 1 summarizes the mean number of eggs identified at the oviposition sites in the presence of banana at different maturity. BSF females laid eggs at both sites with mildly ripened (MR) and fresh banana (OV). Of the total of 6,055 eggs oviposited, 52.67\% (3189/6055) was found at MR and $47.33 \%$
$(2866 / 6055)$ at OV.

Table-1. Mean number of eggs identified at oviposition sites with different maturity of banana.

\begin{tabular}{|l|c|}
\hline $\begin{array}{c}\text { Stages of } \\
\text { maturity }\end{array}$ & Mean number of eggs $( \pm \mathbf{S E})$ \\
\hline Fresh & $591 \pm 105^{\mathrm{a}}$ \\
\hline Mildly Ripened & $797 \pm 209^{\mathrm{a}}$ \\
\hline Over-Ripened & $1032 \pm 293^{\mathrm{b}}$ \\
\hline
\end{tabular}

Rows with the same letters denote no statistical difference $(p>0.05)$

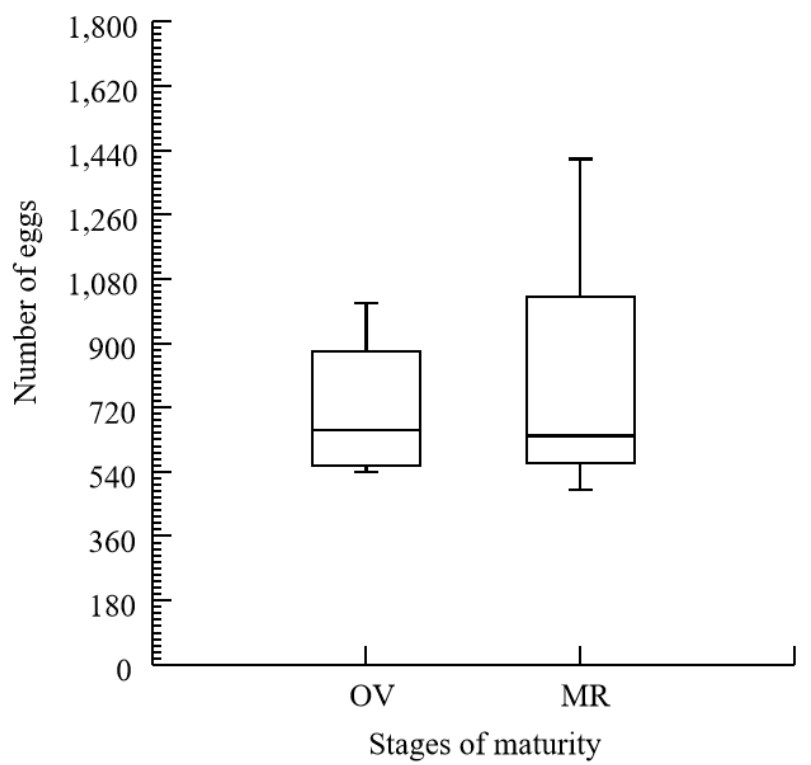

(a) OV vs MR

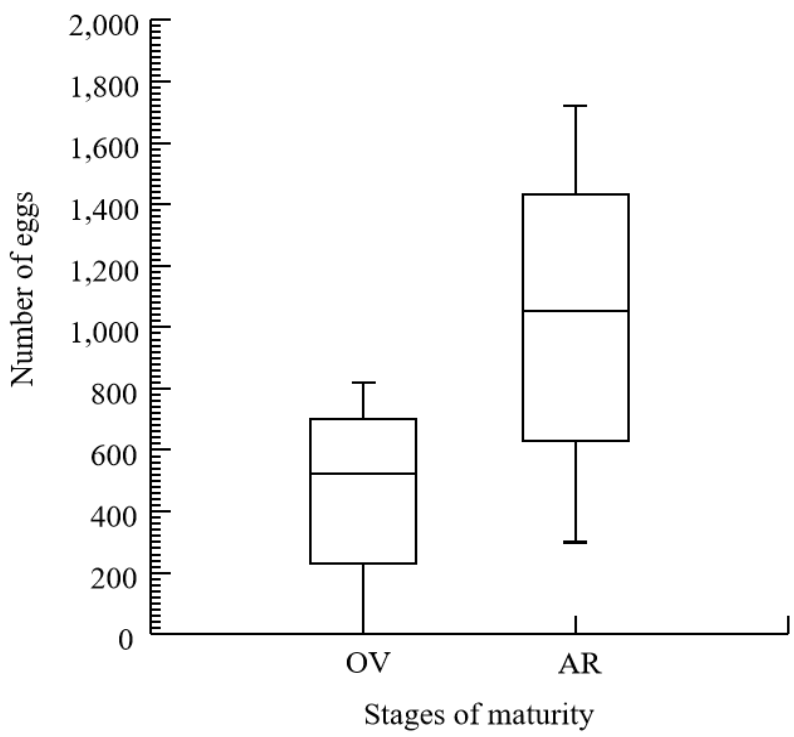

(b) OV vs AR

Figure-2. Box-and-whisker plots for the number of eggs oviposited at $\mathrm{OV}, \mathrm{AR}$ and MR sites 
The mean number of eggs laid at MR (797 \pm 209 eggs, range 491- 1416 eggs) was more than that deposited at OV (717 \pm 108 eggs, range 540- 1013 eggs) (Figure 2a) with the OAI $0.05 \pm 0.32$. When over-ripened bananas (AR) were offered together with fresh bananas (OV), the mean numbers of eggs deposited at the former was higher with a percentage distribution of $68.88 \%$ against $31.12 \%$ (AR: $1032 \pm 293$ eggs, range $300-1720$ eggs; OV: $466 \pm 172$ eggs, range 0 -820 eggs at OV) (Figure 2b). A significant different was confirmed $(\mathrm{p}<0.05)$ in the number of eggs laid at $\mathrm{OV}$ and AR. The OAI calculated was higher $(0.38 \pm$ $0.26)$ than that derived from MR. This suggests overripened bananas are more attractive to BSF.

Table 2 summarizes the oviposition response of BSF in the presence of different abundance of pupae cases. BSF showed preferences to lay eggs at the sites with low (LP) and moderate (MP) abundance of pupae cases where $44.46 \%(1243 / 2796)$ and $42.70 \%$ (1194/2796) of eggs were found at both sites.

Table-2. The mean number of eggs in the presence of different abundance of pupae cases.

\begin{tabular}{|c|c|}
\hline $\begin{array}{c}\text { Abundance of } \\
\text { pupae }\end{array}$ & Mean $( \pm \mathbf{S E})$ \\
\hline $0 \mathrm{~g}(\mathrm{OV})$ & $21 \pm 21^{\mathrm{a}}$ \\
\hline $1 \mathrm{~g}(\mathrm{LP})$ & $311 \pm 42^{\mathrm{b}}$ \\
\hline $5 \mathrm{~g}(\mathrm{MP})$ & $299 \pm 79^{\mathrm{b}}$ \\
\hline $10 \mathrm{~g}(\mathrm{HP})$ & $69 \pm 26^{\mathrm{a}}$ \\
\hline
\end{tabular}

Rows with the same letters denote no statistical difference $(p>0.05)$

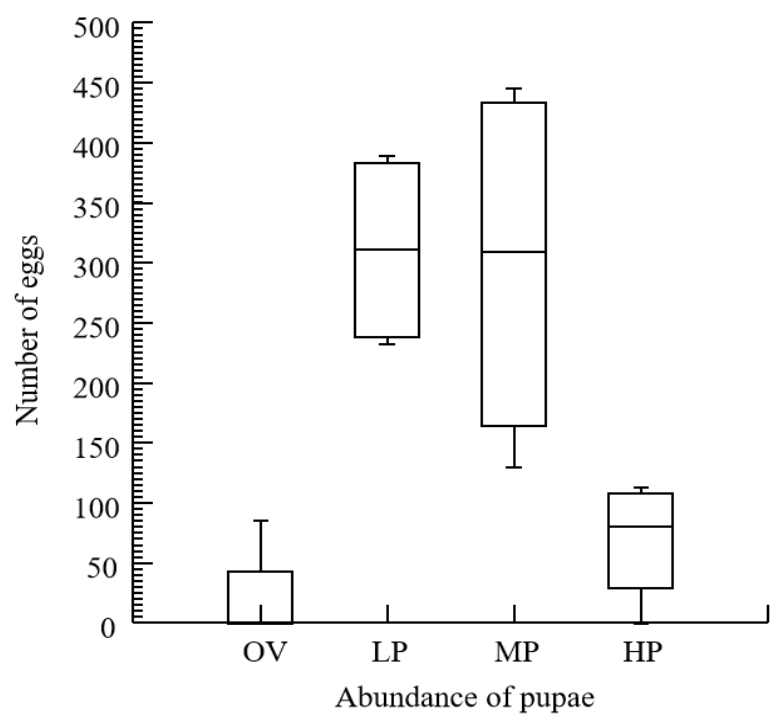

Figure-3. Box-and-whisker plot for the number of eggs oviposited at OV, LP, MP and HP sites
Tukey's test inferred that the oviposition response was significantly influenced by the abundance of pupae cases. The mean number of eggs laid at LP $(311 \pm 42$ eggs; range $232-389$ eggs) and MP (299 \pm 79 eggs; range $130-445$ eggs) were significantly higher than that at OV ( $21 \pm 21$ eggs; range $0-85$ eggs $)$ and HP (69 \pm 26 eggs; range $0-113$ eggs). In terms of attractiveness, LP and MP attained comparable OAI of 0.87 with the latter demonstrating greater variations between replicates. The OAI of HP $(0.53 \pm 0.55)$ however was markedly lower than those sites with less abundance of pupae cases (Figure 3).

\section{Discussion}

Bananas at different maturity were observed to influence the egg laying preference of BSF. Increased number of eggs were found at the sites with ripened bananas (MR and AR) corroborating the observations of Devi and Jha (2017). As the fruit increases in maturity, the odor level intensifies serving to attract BSF. Zvereva and Zhemchuzhina (1988) reported a marked reduction in egg laying response of BSF in the absence of odor. When fresh manure was experimented, an increase in oviposition was conversely observed (Nyakeri et al., 2017b). Odor resulting from fruit ripening is associated with release of ethanol, acetic acid, ethyl acetate and acetaldehyde (Aldana et al., 2013; Zhou et al., 2013). The level of sugar increases markedly in ripened banana, escalating from $1-2 \%$ in fresh pulp and up to $20 \%$ in ripened fruit (Maduwanthi and Marapana, 2017). The ripening also markedly increased protein (Brady et al., 1970), vitamin B, moisture (Rahman et al., 2014), aroma volatiles, and olfactory stimulants (Bangerth et al., 2012). Ovipositors of BSF females are naturally loaded with sensors that allow them to choose the appropriate site for egg deposition (Tomberlin, 2017). The sensory cues for oviposition decisions includes taste, texture, vision and olfaction, of which olfaction is the key factor governing the decision-making (Markow and O'Grady, 2008; Zhu et al., 2014).

The presence of pupal cases was also evidenced to affect the egg-laying response of BSF. The control (OV) and sites with high abundance of pupal cases (HP) were noticeably less attractive to ovipositing BSF females when in competition with LP and MP. Female BSF obviously reject HP in favor of LP and MP. Bradley and Sheppard (1984) examined the oviposition preference of houseflies in the presence of larvae; oviposition sites with a higher larval density 


\section{Pei Chin Tan and Siong Fong Sim}

deterred the houseflies. Horng (1997) inferred that the degree of larval competition could have contributed to the egg-laying decisions. The ovipositing BSF preferred sites with lower abundance of pupal cases possibly perceiving a lower degree of competition (Werner and Gilliam, 1984; Kershenbaum et al., 2012). This oviposition decisions corroborates the behavior of insects in optimizing their offspring growth potential (Allgood and Yee, 2017) and fitness (Binckley and Resetarits, 2005). Among the sites with different abundance of pupae cases, OV (the control) is the least attractive. At the sites filled with pupae cases, it is hypothesized that pheromones may have been released from the pupae cases, acting to attract/repel the ovipositing BSF. Larvae BSF was found to release pheromones serving as deterrent to houseflies (Liu et al., 2019) and pheromones were also extracted from pupal cases of Dolichovespula media (Vander Meer et al., 2019).

\section{Conclusion}

The results of the present study indicated that overripened banana is more attractive to ovipositing BSF females due to stronger odor. This implies that decomposed food is a more effective baiting source for BSF oviposition. Besides, the number of eggs found at oviposition sites with high abundance of pupae cases was seemingly lower as the density may be an indication of competition. The findings suggested that removal of pupal remnants from BSF rearing facilities is necessary and could improve the egg collection efficiency. The findings of this study is important for development of effective egg trapping and collection strategies in BSF farming.

\section{Acknowledgement}

The authors would like to thank Universiti Malaysia Sarawak for supporting this project.

Disclaimer: None.

Conflict of Interest: None.

Source of Funding: This project was financially supported by Universiti Malaysia Sarawak, Malaysia.

\section{References}

Aldana J, Quan E, Vickerson A, Marchant B, Kaulfuss $\mathrm{O}$ and Radley $\mathrm{R}$, inventors; Enterra Feed Corporation, assignee. 2013 May 7. Contained systems to provide reproductive habitat for Hermetia illucens. U.S. patent 9,510,572.

Allgood DW and Yee DA, 2017. Oviposition preference and offspring performance in container breeding mosquitoes: evaluating the effects of organic compounds and laboratory colonisation. Ecol. Entomol. 42(4): 506-516.

Badenhorst R, 2017. Genetic diversity in a commercial black soldier fly, Hermetia illucens (Diptera: Stratiomydiae), population. Ph.D. dissertation, Stellenbosch University, Stellenbosch.

Bangerth FK, Song J and Streif J, 2012. Physiological impacts of fruit ripening and storage conditions on aroma volatile formation in apple and strawberry fruit: a review. Hort. Sci. 47(1): 4-10.

Binckley CA and Resetarits WJ, 2005. Habitat selection determines abundance, richness and species composition of beetles in aquatic communities. Biol. Lett. 1(3): 370-374.

Bradley SW and Sheppard DC, 1984. House fly oviposition inhibition by larvae of Hermetia illucens, the black soldier fly. J. Chem. Ecol. 10: 853-859.

Brady CJ, O'connell PBH, Smydzuk J and Wade NL, 1970. Permeability, sugar accumulation, and respiration rate in ripening banana fruits. Australian J. Biol. Sci. 23(5): 1143-1152.

Chia SY, Tanga CM, Khamis FM, Mohamed SA, Salifu D, Sevgan S, Fiaboe KKM, Niassy S, van Loon JJA, Dicke M and Ekesi S, 2018. Threshold temperatures and thermal requirements of black soldier fly Hermetia illucens: implications for mass production. PLoS One. 13(11): e0206097.

Devi AR and Jha S, 2017. Oviposition tendency of Bactrocera dorsalis (Diptera: Tephritidae) infesting guava (Psidium guajava L.) in relation to fruit ripening stages. Int J. Pure Appl. Biosci. 5(4): 1869-1875.

Diener S, Zurbrügg C and Tockner K, 2009. Conversion of organic material by black soldier fly larvae: establishing optimal feeding rates. Waste Manage. Res. 27(6): 603-610.

Dieng H, Satho T, Abang F, Miake F, Ghani IA, Latip NA, Aliasan NE, Noor S, Ahmad AH, Ahmad H, Zuharah WF, Majid AHA, Nolasco-Hipolito C, Enrique Morales Vargas R, Phumala Morales $\mathrm{N}$ and Noweg GT, 2017. Anti-oviposition activities of used sock media against a dengue vector: prospects of eco-friendly control and solutions to pollution. Environ. Sci. Pollut. Res. Int. 24(26): 21375-21385. 
Driemeyer H, 2016. Evaluation of black soldier fly (Hermetia illucens) larvae as an alternative protein source in pig creep diets in relation to production, blood and manure microbiology parameters. Ph.D. dissertation, Stellenbosch University, Stellenbosch.

Horng SB, 1997. Larval competition and egg-laying decisions by the bean weevil, Callosobruchus maculatus. Anim. Behav. 53(1): 1-12.

Kershenbaum A, Spencer M, Blaustein L and Cohen JE, 2012. Modelling evolutionarily stable strategies in oviposition site selection, with varying risks of predation and intraspecific competition. Evol. Ecol. 26(4): 955-974.

Kramer WL and Mulla MS, 1979. Oviposition attractants and repellents of mosquitoes: oviposition responses of Culex mosquitoes to organic infusions. Environ. Entomol. 8(6): 11111117.

Lalander CH, Komakech AJ and Vinnerås B, 2015. Vermicomposting as manure management strategy for urban small-holder animal farms Kampala case study. Waste Manage. 39: 96-103.

Liu C, Wang C and Yao H, 2019. Comprehensive resource utilization of waste using the black soldier fly (Hermetia illucens (L.))(Diptera: Stratiomyidae). Animals. 9(6): 349.

Maduwanthi SDT and Marapana RAUJ, 2017. Biochemical changes during ripening of banana: a review. Int. J. Food Sci. Nutr. 2(5): 166-170.

Markow TA and O'Grady P, 2008. Reproductive ecology of Drosophila. Funct. Ecol. 22: 747-759.

Moula N, Hornick JL, Cabaraux JF, Korsak N, Daube G, Dawans E, Antoine N, Taminiau B and Detilleux J, 2018. Effects of dietary black soldier fly larvae on performance of broilers mediated or not through changes in microbiota. J. Insects Food Feed. 4(1): 31-42.

Newton L, Sheppard C, Watson DW, Burtle G and Dove R, 2005. Using the black soldier fly, Hermetia illucens, as a value-added tool for the management of swine manure. (http://www.organicvaluerecovery.com/s tudies/studies_htm_files/bsf_value_added.pdf).

Nguyen TT, Tomberlin JK and Vanlaerhoven S, 2015. Ability of black soldier fly (Diptera: Stratiomyidae) larvae to recycle food waste. Environ. Entomol. 44(2): 406-410.

Nyakeri EM, Ogola HJO, Ayieko MA and Amimo FA, 2017a. Valorisation of organic waste material: growth performance of wild black soldier fly larvae (Hermetia illucens) reared on different organic wastes. J. Insects Food Feed. 3(3): 193202.

Nyakeri EM, Ogola HJO, Ayieko MA and Amimo FA, 2017b. Comparison of the performance of different baiting attractants in the egg laying activity of the black soldier fly (Hermetia illucens L.). J. Entomol. Zool. Stud. 5(6): 1583-1586.

Oonincx DG, Van Broekhoven S, Van Huis A and van Loon JJ, 2015. Feed conversion, survival and development, and composition of four insect species on diets composed of food byproducts. PLoS One. 10(12): e0144601.

Park K, Kim W, Kim E, Kwak K-W, Choi J-Y, Lee S, Song M and Kim S-H, 2016. Oviposition site preference in black soldier fly, Hermetia illucens (Diptera: Stratiomyidae), in artificial rearing system. Int. J. Indust. Entomol. 33(2): 54-58.

Rahman AS, Islam MN, Imtiaz MY, Pasha AF, Mursalat M, Alam SS and Khan MS, 2014. Nutrition value analysis of artificially ripened banana (bari-1 hybrid banana, Musa spp.), pp. 172-176. In Proceedings, the International Conference on Chemical Engineering, 29-30 December 2014, Dhaka, Bangladesh.

Rumpold BA and Schlüter OK, 2013. Nutritional composition and safety aspects of edible insects. Mol Nutr. Food Res. 57(5): 802-823.

Sheppard DC, Tomberlin JK, Joyce JA, Kiser BC and Sumner SM, 2002. Rearing methods for the black soldier fly (Diptera: Stratiomyidae). J. Med. Entomol. 39(4): 695-698.

Tomberlin JK, 2017. How do I get black soldier flies to lay eggs in a location of my choosing? hintcheck your microbes. (https://www.evoconsys.com/blog/how -do-i-getblack-soldier-flies-to-lay-eggs-in-a-location-ofmy-choosing-hint-check-your-microbes)

Tomberlin JK and Sheppard DC, 2001. Lekking behavior of the black soldier fly (Diptera: Stratiomyidae). Florida Entomol. 84(4): 729-730.

Tomberlin JK and Sheppard DC, 2002. Factors influencing mating and oviposition of black soldier flies (Diptera: Stratiomyidae) in a colony. J. Entomol. Sci. 37(4): 345-352.

Tomberlin JK, Sheppard DC and Joyce JA, 2005. Black soldier fly (Diptera: Stratiomyidae) colonization of pig carrion in South Georgia. J. Forensic Sci. 50(1): 152-153.

Van Huis A, Van Itterbeeck J, Klunder H, Mertens E, Halloran A, Muir G and Vantomme P, 2013. 
Edible insects: future prospects for food and feed security (No. 171). FAO, Rome.

Vander Meer RK, Breed MD, Winston M and Espelie KE, 2019. Pheromone communication in social insects: ants, wasps, bees, and termites. CRC Press, Boca Raton, FL.

Wang YS and Shelomi M, 2017. Review of black soldier fly (Hermetia illucens) as animal feed and human food. Foods. 6(10): 91.

Werner EE and Gilliam JF, 1984. The ontogenetic niche and species interactions in size-structured populations. Ann. Rev. Ecol. Syst. 15(1): 393 425.

Zhou F, Tomberlin JK, Zheng L, Yu Z and Zhang J, 2013. Developmental and waste reduction plasticity of three black soldier fly strains (Diptera: Stratiomyidae) raised on different livestock manures. J. Med. Entomol. 50(6): 1224 1230.
Zhu EY, Guntur AR, He R, Stern U and Yang CH, 2014. Egg-laying demand induces aversion of UV light in Drosophila females. Curr. Biol. 24(23): 2797-2804.

Zvereva EL and Zhemchuzhina AA, 1988. On some factors influencing the Musca domestica L. fecundity. Medskaya Parazitol. 58: 27-30.

\section{Contribution of Authors}

Tan PC: Designed research methodology, conducted experiment, collected data and wrote article

Sim SF: Helped in data collection and analysis, article write up and final approval 